\title{
ESTABLISHMENT OF COCKAYNE SYNDROME FIBROBLAST CELL LINE BELONGING TO COMPLEMENTATION GROUP B BY SV40 TRANSFORMATION
}

\author{
Kiyoji Tanaka, ${ }^{1,2, *}$ Kazuhiko Kawai, ${ }^{1}$ Yuichi Kumahara, ${ }^{1}$ \\ Tsuyoshi UCHIDA, ${ }^{2}$ and Yoshio OKADA ${ }^{2}$ \\ ${ }^{1}$ Department of Medicine and Geriatrics, Osaka University Medical School, \\ Fukushima, Osaka 553, Japan \\ ${ }^{2}$ Institute for Cellular and Molecular Biology, Osaka University, \\ Yamada-oka, Suita 565, Japan
}

\begin{abstract}
Summary A permanent fibroblast cell line of Cockayne syndrome (CS) belonging to complementation group B (CS1BESV) was established by simian virus 40 (SV40) transformation. The ultraviolet light (UV)-sensitivity of CS1BESV was similar to that of parental primary CS1BE fibroblast. The recovery of the rate of semiconservative DNA synthesis after UV-irradiation $\left(12 \mathrm{~J} / \mathrm{m}^{2}\right)$ was absent in CSIBESV. With respect to the rate of semiconservative DNA synthesis after UV-irradiation $\left(12 \mathrm{~J} / \mathrm{m}^{2}\right)$, CSIBESV complemented the primary fibroblast of group A CS (CS3BE) but not group B CS (CS1BE), confirming that CS1BESV belongs to complementation group B. The CS1BESV cells were transfected with recombinant vectors (pSV2gpt) carrying the Escherichia coli xanthine-guanine phosphoribosyltransferase gene (Ecogpt). They exhibited stable transformation frequency of $1 \times 10^{-3}$. The CSIBESV cells will be useful as a permanent source of supply of parental group B CS cells for genetic complementation tests of CS and as a DNA transfer recipient for cloning of the gene which is deficient in CS.
\end{abstract}

\section{INTRODUCTION}

Cockayne syndrome (CS) is a rare autosomal recessive disorder characterized by cachectic dwarfism, precocious senile appearance, microcephaly, deafness, progressive mental retardation, pigmentary retinal degeneration, optic atrophy, and skin hypersensitivity to sunlight. Cultured skin fibroblasts from patients with CS (CS cells) have been shown to be more sensitive to ultraviolet light (UV) than those from normal donors, in terms of colony forming ability (Schmickel et al., 1977)

Received October 28, 1984

* To whom all correspondences should be addressed at Institute for Cellular and Molecular Biology. 
and of cellular capacity to recover DNA and RNA synthesis after UV-irradiation (Ikenaga et al., 1981; Lehmann et al., 1979; Mayne and Lehmann, 1982). On the basis of recovery of DNA and RNA synthesis after UV-irradiation, CS cell strains have been classified into three different complementation groups (A, B, and C) (Tanaka et al., 1981; Lehmann, 1982). However, no defect has been detected in the ability to carry out excision repair (Schmickel et al., 1977; Andrews et al., 1978; Cleaver, 1982), or post-replication repair (Hoar and Waghorne, 1978) in CS. To elucidate the genetic defect(s) in CS, it seems necessary to isolate the gene(s) responsible for the defect in CS. One of the ways to accomplish this purpose is the transfer of the normal human DNA into CS cells to obtain the UV-resistant (genetically transformed) CS cells and the subsequent rescue of the responsible transforming gene from them. As a DNA transfer recipient, we need the permanent CS cell line which shows high transformation frequency. We intended to establish the CS fibroblast cell line by simian virus 40 (SV40) transformation and succeeded in the establishment of a permanent fibroblast cell line of CS belonging to complementation group B which showed high transformation frequency with pSV2gpt, a recombinant vector carrying the Escherichia coli xanthine-guanine phosphoribosyltransferase gene (Ecogpt).

\section{MATERIALS AND METHODS}

1) Cell strains. The cell strains used in this study are presented in Table 1 . CS cell strains, CS1BE (GM1629) and CS3BE (GM1856) were obtained from the Human Genetic Mutant Cell Repository, Institute for Medical Research, Camden, N.J. Strain NHKK was derived from a 29-year-old normal male. Cells were grown in Dulbecco's modified medium (DME) supplemented with $10 \%$ fetal calf serum (microbiological associate) in $5 \% \quad \mathrm{CO}_{2}$ in a $37^{\circ} \mathrm{C}$ incubator. SV40 transformed CS cell line, CSIBESV, was cultured in DME containing 3 or $5 \%$ fetal calf serum.

2) Viruses, DNA and chemicals. HVJ (hemagglutinating virus of Japan), Z strain, propagated in embryonated eggs, was partially purified by differential centrifugation and suspended in buffered salt solution (BSS) $(0.14 \mathrm{M} \mathrm{NaCl}, 5.4 \mathrm{~mm}$

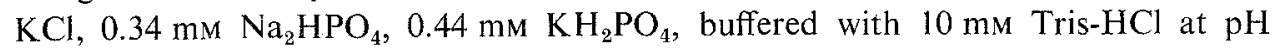
8.0). HVJ was UV-inactivated before use (Okada and Murayama, 1966). SV40, strain 777 wild type, was kindly provided by Dr. A. Hakura, Osaka University. The pSV2gpt was kindly provided by Dr. P. Berg, Stanford University. Salmon

Table 1. Human skin fibroblast cell strains.

\begin{tabular}{lccc} 
Cell strain & Sex & Age (yrs) & Genotype \\
\hline CS1BE (GM1629) & F & 10 & CS homozygote \\
CS3BE (GM1856) & M & 13 & CS homozygote \\
NHKK & M & 29 & normal control \\
\hline
\end{tabular}


testis DNA, hypoxanthine, thymidine and colcemid were purchased from Sigma Chemical Company. Aminopterin and xanthine were purchased from Wako Pure Chemical Industries and P-L Biochemicals Inc., respectively. Mycophenolic acid was kindly provided by Eli Lilly and Company.

3) Chromosome analysis. Exponentially growing CSIBESV cells were cultured in DME containing 5\% fetal calf serum. Colcemid solution was added to the final concentration of $0.1 \mu \mathrm{g} / \mathrm{ml}$ and cells were incubated for $2 \mathrm{hr}$ at $37^{\circ} \mathrm{C}$. Cells harvested with trypsin and EDTA were spun down and resuspended in $75 \mathrm{~mm} \mathrm{KCl}$ solution followed by incubation at room temperature for $10 \mathrm{~min}$. Then 2 or 3 volumes of freshly prepared fixative solution (methanol : acetic acid, $3: 1$ ) was added with gentle pipetting. These fixation procedures were repeated 3 times. Finally a small volume of fixative solution was added to the centrifuged residual cell pellet. One drop of this cell suspension was dropped onto microscope slide glass and allowed to air dry. This preparation was stained with Giemsa and the number of chromosome in 50 metaphase cells was counted under TV display $(\times 1,000 \mathrm{mag}-$ nification).

4) UV-survival. CS and normal cells were inoculated into plastic Petri dishes (60 $\mathrm{mm}$ diameter dish for SV40 transformed cell line, and $100 \mathrm{~mm}$ diameter dish for primary cell strains) $7-8 \mathrm{hr}$ before UV-irradiation. For UV-irradiation, dishes were washed with Dulbecco's phosphate buffered saline (PBS), aspirated and UVirradiated by one or three $10 \mathrm{~W}$ germicidal lamp(s) (Toshiba) at a dose rate of 0.45 $\mathrm{J} / \mathrm{m}^{2} / \mathrm{sec}$ or $1.4 \mathrm{~J} / \mathrm{m}^{2} / \mathrm{sec}$. After $\mathrm{UV}$-irradiation, dishes were incubated in a $\mathrm{CO}_{2}$ incubator for 7-14 days with medium renewal every 3 days. The colonies which arose were then fixed, stained with Giemsa and counted by eye.

5) SV40 infection. Primary skin fibroblasts, CSIBE, at 9th passage were inoculated at a density of $4 \times 10^{5}$ cells per $60 \mathrm{~mm}$ Petri dish and incubated for 3 days in DME containing $10 \%$ fetal calf serum. The cells were then infected by $5 \times 10^{7} \mathrm{SV} 40$ virions (strain 777 wild type) in $0.5 \mathrm{ml}$ of DME for $2 \mathrm{hr}$ at $37^{\circ} \mathrm{C}$ with rocking every $30 \mathrm{~min}$ and the next day, the cells in a dish were transferred into 3 dishes. Four weeks after SV40 infection, the foci were observed. The whole cells in Petri dishes containing foci were split into new Petri dishes at one-tenth ratio in DME containing 3\% fetal calf serum. When the cells reached confluence, onetenth of the cells were again transferred and such subculture was continued until a permanent CS cell line appeared.

6) Complementation analysis. CS1BESV and CS1BE or CS3BE cells were fused by UV-inactivated HVJ as described (Tanaka et al., 1981). The fused cells were cultured for $18 \mathrm{hr}$ in DME containing $5 \%$ fetal calf serum, then irradiated with $12 \mathrm{~J} / \mathrm{m}^{2}$ of UV at a dose rate of $1.4 \mathrm{~J} / \mathrm{m}^{2} / \mathrm{sec}$. The cultures were then incubated for $12 \mathrm{hr}$ followed by pulse-labeling with $0.3 \mu \mathrm{Ci} / \mathrm{ml}$ of $\left[{ }^{3} \mathrm{H}\right]$ thymidine $(20 \mathrm{Ci} / \mathrm{mmol}$; Amersham) for $15 \mathrm{~min}$. After pulse-labeling, the cultures were washed with PBS, fixed with methanol and processed for autoradiography as described (Tanaka et al., 1981). 
7) DNA transfection. CS cell line, CSIBESV was transfected by pSV2gpt (circular form) as described (Wigler et al., 1978), except that dimethyl sulfoxide treatment was omitted and 15\% (weight/volume) glycerol in HEPES buffered saline (0.125 M NaCl, $0.75 \mathrm{mM} \mathrm{Na}_{2} \mathrm{HPO}_{4}, 0.75 \mathrm{~mm} \mathrm{NaH} \mathrm{PO}_{4}, 25 \mathrm{~mm}$ HEPES-NaOH, pH 7.1) was added for $30 \mathrm{sec}$ about $12 \mathrm{hr}$ after DNA addition. The cells were then washed with DME, re-fed with DME containing $5 \%$ fetal calf serum. Three to five days after glycerol treatment, the cells were harvested and re-inoculated into new Petri dishes containing 5\% fetal calf serum DME HATX MPA $(15 \mu \mathrm{g} / \mathrm{ml}$ hypoxanthine, $2 \mu \mathrm{g} / \mathrm{ml}$ aminopterin, $10 \mu \mathrm{g} / \mathrm{ml}$ thymidine, $250 \mu \mathrm{g} / \mathrm{mi}$ xanthine, 10 g/ml mycophenolic acid). About 10-14 days later the cultures were fixed and stained with Giemsa.

\section{RESULTS}

About 7 months after SV40 infection when the rate of doubling of the whole population was reduced and senescent cells appeared in the population, packed colonies which consisted of actively dividing cells appeared. When one-tenth of this culture was transferred into new Petri dish, homologous epithelial-like cells grew rapidly and occupied the dish in a week. They were then plated for cellular cloning in DME containing 3\% fetal calf serum. One of the biggest colonies was pickedup. This clone continued to divide rapidly for more than 6 months and was thought to become a cell line. This clone was named as CSIBESV and used for the following experiments.

The morphology of CSIBESV cells is shown in Fig. 1. The histogram of chromosome numbers per cell are shown in Fig. 2. The modal number of chromosome was 77 per cell. It is interesting that the SV40-transformed human fibroblast cell

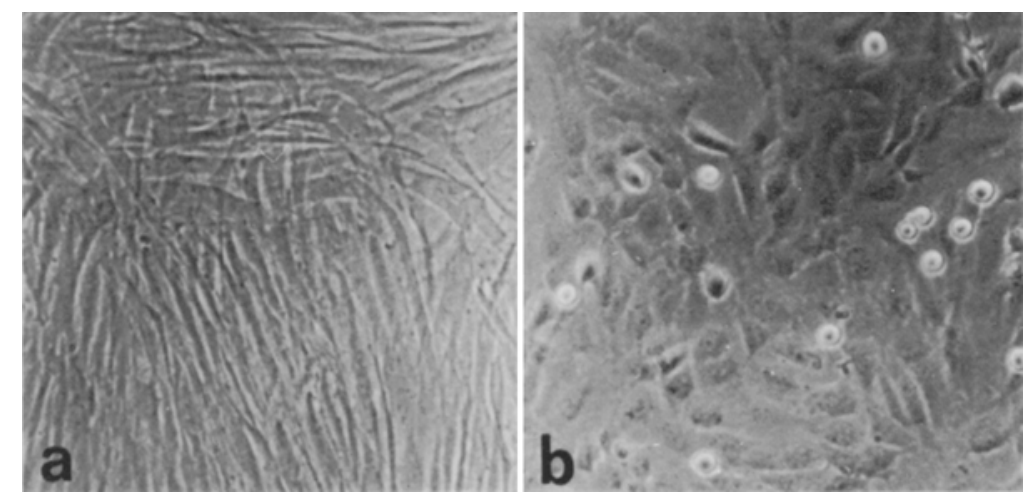

Fig. 1. Morphology of primary skin fibroblast, CSIBE (passage 9) and SV40-transformed fibroblast cell line, CS1BESV ( 400 magnification). (a) Confluent monolayer of CS1BE showing spindle shape of fibroblast in culture. (b) Monolayer of CS1BESV showing rounded cell morphology with many metaphases. 
lines (WI38VA13, XP2OSSV, XP2YOSV, and CS1BESV) have almost the same modal number of chromosome (70-80) (American Type Culture Collection catalogue, Dr. K. Ishizaki; Kyoto University: personal communication, Yagi and Takebe, 1983, and our present data, respectively).

Figure 3 shows cell survival as a function of UV-dose for CSIBESV and paren-

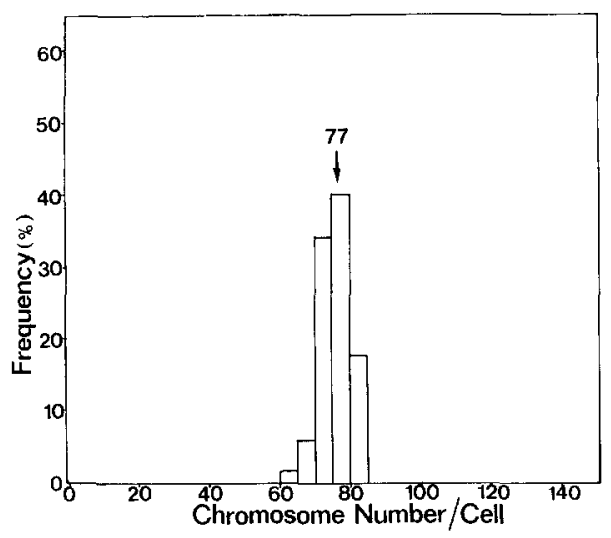

Fig. 2. Histogram of chromosome numbers per cell. 50 metaphases were scored. The mean number of chromosomes is shown by an arrow and number.

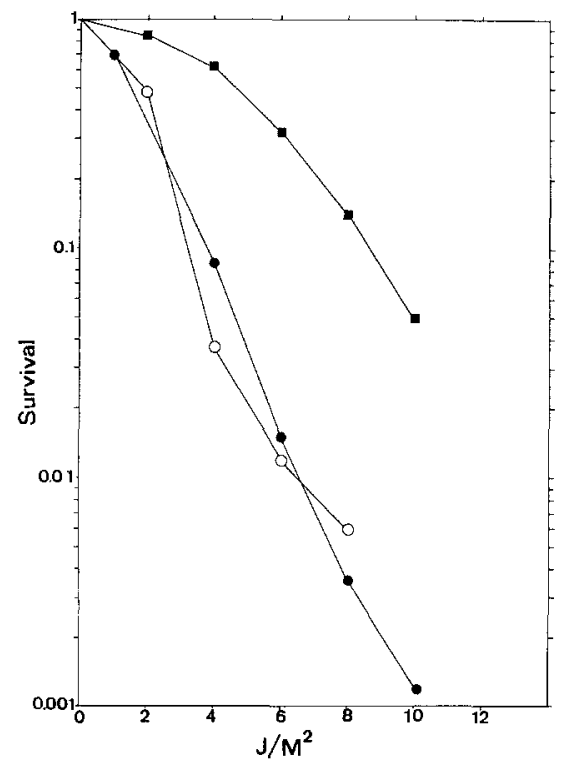

Fig. 3. UV sensitivity as measured by colony-forming ability in CS and normal human cells. All points are the averages of duplicate plates. $\mathbf{n}$, NHKK; $\bullet$ CS3BE; $O$, CS3BESV. Plating efficiencies of cells were $4.5 \%$ in NHKK, $10.0 \%$ in CS1BE and $32.8 \%$ in CS1BESV cells. 
tal CSIBE cells. The UV-sensitivity of CSIBESV was similar to that of CSIBE. Both were about 3 times more UV-sensitive than normal human cells.

The rate of semiconservative DNA synthesis in CSIBESV after $12 \mathrm{~J} / \mathrm{m}^{2}$ UVirradiation is shown in Fig. 4. In agreement with previous observation of primary CS strains (Schmickel et al., 1977), the recovery of the rate of semiconservative DNA synthesis after $12 \mathrm{~J} / \mathrm{m}^{2}$ of UV-irradiation in CSIBESV cells was not observed even 12-24 hr after UV-irradiation, while that in normal human cells reached values $80-150 \%$ of those of unirradiated normal human cells.

To confirm that CSIBESV cells retain the genetic characteristics of complementation group B CS, they were fused to primary CS1BE (group B) or CS3BE (group A) cells by the aid of HVJ. After $18 \mathrm{hr}$, the cultures were irradiated with $12 \mathrm{~J} / \mathrm{m}^{2}$ $\mathrm{UV}$ and incubated for $12 \mathrm{hr}$ at $37^{\circ} \mathrm{C}$ and then pulse-labeled with $0.3 \mu \mathrm{Ci} / \mathrm{ml}$ of $\left[\mathrm{H}^{3}\right]$ thymidine for $15 \mathrm{~min}$. As shown in Fig. 5, the recovery of the rate of semiconservative DNA synthesis was observed in the binuclear cells obtained by fusion of CSIBESV and CS3BE, but not detected in the binuclear cells obtained by fusion of CSIBESV and CS1BE. These results indicate that CSIBESV cells retained the same genetic characteristics as those of parental CS1BE cells.

CS1BESV cells were then transfected with pSV2gpt. The monolayers of CS1BESV cells $\left(10^{6}\right.$ cells/dish) were treated with $5 \mu \mathrm{g}$ of pSV2gpt and $15 \mu \mathrm{g}$ of salmon testis DNA, followed by $15 \%$ glycerol treatment and 3 days incubation in normal media. The caltures $\left(5 \times 10^{5}\right.$ cells/dish) were then exposed to selection media of mycophenolic acid ( $5 \%$ fetal calf serum DME HATX MPA). After 1014 days, the colonies which arose were fixed, stained by Giemsa and counted by eye.

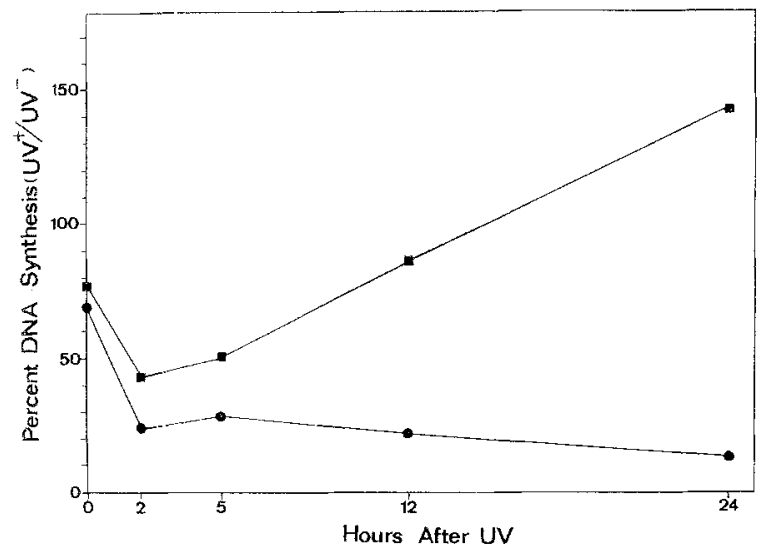

Fig. 4. Rate of semiconservative DNA synthesis following UV irradiation. Cells were seeded on cover glass in dish, grown for three days prior to exposure to $12 \mathrm{~J} / \mathrm{m}^{2}$ of $\mathrm{UV}$, and pulse-labeled for $15 \mathrm{~min}$ with $0.3 \mu \mathrm{Ci} / \mathrm{ml}$ of $\left[\mathrm{H}^{3}\right]$ thymidine at the times indicated on the abscissa. The ordinate shows the rate of DNA synthesis determined by mean grain count per nucleus as a percentage of unirradiated control.

a, NHKK; - CSIBESV. 


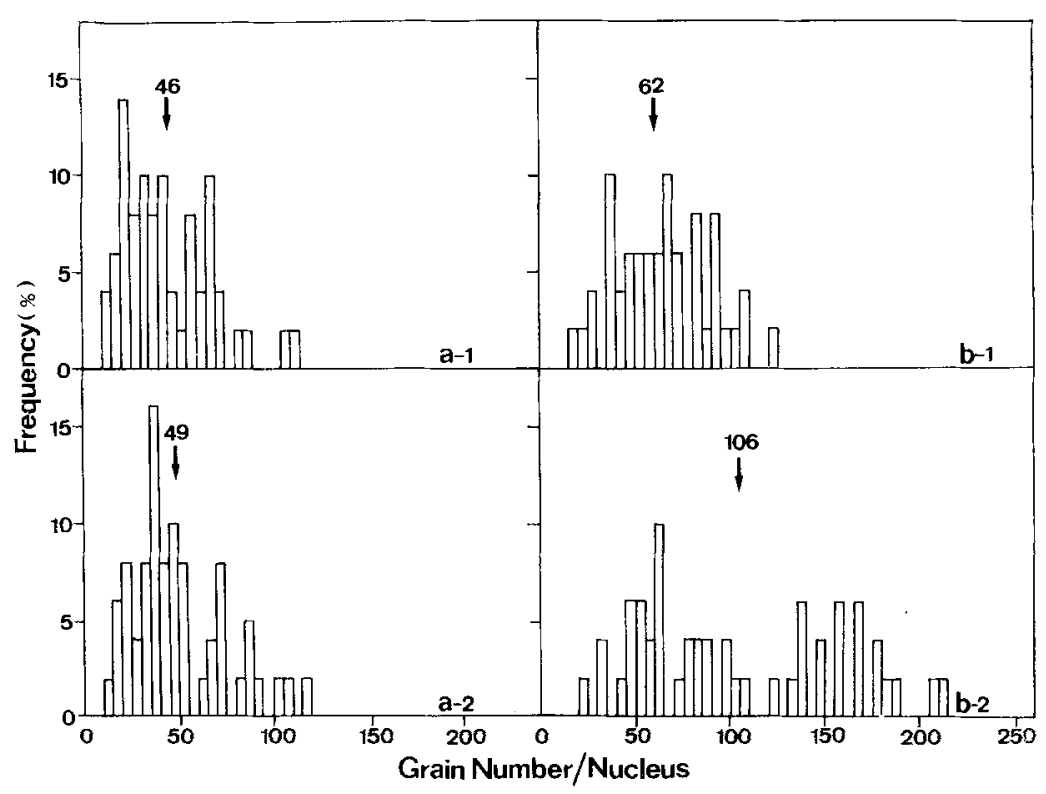

Fig. 5. Histograms showing the distribution of grain counts (the rate of DNA synthesis at $12 \mathrm{hr}$ after $12 \mathrm{~J} / \mathrm{m}^{2}$ of UV irradiation) in mononuclear (1) and binuclear (2) cells obtained by fusion of the mixture of CS1BE and CS1BESV (a) and the mixture of CS3BE and CS1BESV with HVJ. The ordinate indicates the frequency of nuclei with the grain counts shown on the abscissa. Each arrow indicates the mean grain count for 100 consecutively evaluated nuclei of each histogram.

Table 2. pSV2gpt transformation frequency in CS1BESV cells.

\begin{tabular}{cc}
\hline Experiment & Colonies per $5 \times 10^{5}$ cells \\
\hline 1 & 460,446 \\
2 & 603,511 \\
\hline
\end{tabular}

The results are shown in Table 2. Stable Ecogpt transformants were obtained with an efficiency of $1 \times 10^{-3}$. These results indicate that CS1BESV cells are very good recipients for DNA transfer.

\section{DISCUSSION}

We established the CS fibroblast cell line belonging to complementation group B by SV40 transformation. It will be useful as a permanent source of supply of parental group B CS cells for genetic complementation analysis of CS as described in the RESULTS.

Our CS cell line exhibited a high genetic transformation frequency of $1 \times 10^{-3}$ 
with pSV2gpt. Gorman et al. (1983) also showed that primate cells (XP2OSSV: SV40-transformed group A xeroderma pigmentosum cells, and HeLa cells) were transformed with pSV2gpt at the frequency of $1 \times 10^{-3}$. DNA-mediated introduction of genes into mammalian cells is an important method for gene cloning, as illustrated by numerous recent papers reporting isolation of cellular oncogenes (Cooper, 1982; Weinberg, 1982; Bishop, 1983; Land et al., 1983). Rubin et al. (1983) and MacInnens et al. (1984) recently reported successful transformation of DNA repair-deficient Chinese hamster ovary (CHO) mutant cells by the co-transfection with normal human genomic DNA and pSV2gpt. Very recently, Westerveld et al. (1984) succeeded in the molecular cloning of a human repair gene that complements the repair defect in $\mathrm{CHO}$ mutant cells. However, their cloned gene failed to complement the defect of xeroderma pigmentosum cells (Dr. H. Takebe, personal communication). To isolate the responsible gene for the defect in xeroderma pigmentosum or CS cells, it may be better to use xeroderma pigmentosum or CS cells as DNA transfer-recipients. Rubin et al. (1983) reported that the frequency of Ecogpt transformant of their CHO mutant cells were $3 \times 10^{-4}-2 \times 10^{-3}$ and the cotransfer frequency (both Ecogpt and DNA repair gene) in successful experiments were $6 \times 10^{-8}-2 \times 10^{-7}$. Therefore, XP2OSSV and our CS1BESV cells can be used as gene transfer-recipients for the cloning of the DNA repair genes which are deficient in xeroderma pigmentosum and CS. The co-transfection experiments of XP2OSSV and CS1BESV cells with normal human or mouse DNA and pSV2gpt are in progress.

\section{REFERENCES}

Andrews, A.D., Barrett, S.F., Yoder, F.W., and Robbins, 3.H. 1978. Cockayne's syndrome fibroblasts have increased sensitivity to ultraviolet light but normal rates of unscheduled DNA synthesis. J. Invest. Dermatol. $70: 237-239$.

Bishop, J.M. 1983. Cancer genes come of age. Cell 32: 1018-1020.

Cleaver, J.E. 1982. Normal reconstruction of DNA supercoiling and chromatin structure in Cockayne syndrome cells during repair of damage from ultraviolet light. Am. J. Hum. Genet. 34: $566-575$.

Cooper, G.M. 1982. Cellular transforming genes. Science 218: 801-806.

Gorman, C., Padmanabhan, R., and Howard, B.H. 1983. High efficiency DNA mediated transformation of primate cells. Science 221: 551-553.

Hoar, D.I. and Waghorne, C. 1978. DNA repair in Cockayne syndrome. Am. J. Hum. Genet. 30: $590-601$.

Ikenaga, M., Inoue, M., Kozuka, T., and Sugita, T. 1981. The recovery of colony forming ability and the rate of semi-conservative DNA synthesis in ultraviolet-irradiated Cockayne and normal human cells. Mutat. Res. 37: 87-91.

Land, H., Parada, L.F., and Weinberg, R.A. 1983. Cellular oncogenes and multistep carcinogenesis. Science 222: 771-778.

Lehmann, A.R., Kirk-Bell, S., and Mayne, L.V. 1979. Abnormal kinetics of DNA synthesis in ultraviolet light-irradiated cells from patients with Cockayne syndrome. Cancer Res. 39:42374241 . 
Lehmann, A.R. 1982. Three complementation groups in Cockayne syndrome. Mutat. Res. 106: $347-356$.

MacInnes, M.A., Bingham, J.M., Thompson, L.H., and Strniste, G.F. 1984. DNA-mediated cotransfer of excision repair capacity and drug resistance into Chinese hamster ovary mutant cell line UV-135. Mol. Cell. Biol. 4: 1152-1158.

Mayne, L.V. and Lehmann, A.R. 1982. Failure of RNA synthesis to recover after UV irradiation: An early defects in cells from individuals with Cockayne's syndrome and xeroderma pigmentosum. Cancer Res. 42: 1473-1478.

Okada, Y. and Murayama, F. 1966. Requirement of calcium ions for the cell fusion reaction of animal cells by HVJ. Exp. Cell Res. 44: 527-551.

Rubin, J.S., Joyner, A.L., Bernstein, A., and Whitmore, G.F. 1983. Molecular identification of a human DNA repair gene following DNA-mediated gene transfer. Nature 306: 206-208.

Schmickel, R.D., Chu, E.H.Y., Trosko, J.E., and Chang, C.C. 1977. Cockayne syndrome: A cellular sensitivity to ultraviolet light. Pediatrics 60: 135-139.

Tanaka, K., Kawai, K., Kumahara, Y., Ikenaga, M., and Okada, Y. 1981. Genetic complementation groups in Cockayne syndrome. Somat. Cell Genet. $7:$ 445-455.

Weinberg, R.A. 1982. Fewer and fewer oncogenes. Cell 30: 3-4.

Westerveld, A., Hoeijmakers, J.H.J., van Duin, M., de Wit, J., Odijk, H., Pastink, A., Wood, R.D., and Bootsma, D. 1984. Molecular cloning of a human DNA repair gene. Nature 310: 425429.

Wigler, M., Pellicer, A., Silverstein, S., and Axel, R. 1978. Biochemical transfer of single-copy eukaryotic genes using total cellular DNA as donor. Cell 14: 725-731.

Yagi, T. and Takebe, H. 1983. Establishment by SV40 transformation and characteristics of a cell line of xeroderma pigmentosum belonging to complementation group F. Mutat. Res. 112: 59-66. 